\title{
Differences in the use of outsourcing in public and private institutions providing medical services
}

\author{
Aleksandra I. Czerw, Mariola Kowalska, Urszula Religioni
}

Department of Public Health, Medical University of Warsaw, Poland

Submitted: 24 August 2012

Accepted: 1 December 2012

Arch Med Sci 2014; 10, 3: 618-629

DOI: 10.5114/aoms.2014.43754

Copyright ๑ 2014 Termedia \& Banach
Corresponding author:

Aleksandra I. Czerw PhD Department of Public Health Medical University of Warsaw 61 Zwirki i Wigury St

02-091 Warsaw, Poland

Phone: +48 501176370

E-mail: ola_czerw@wp.pl

\section{Abstract}

Introduction: The costs of health care in Poland are continuously increasing. Thus, almost every institution providing medical services aims at their limitation. One of the costs rationalisation methods in the health care sector is outsourcing.

Material and methods: The study was conducted in 153 randomly selected institutions providing medical activities. The tool was a questionnaire, available via a web browser.

Results: Over $30 \%$ of public institutions identified the need for financial savings, as the main reason for outsourcing the cleaning function. Among private institutions, the dominant reason for this is too high maintenance cost of the cleaning staff (less than $40 \%$ of responses). The huge number of medical institutions use the services of an external company for laundering. Over $30 \%$ of public institutions identified as the most common reason for separation of functions laundering lack of resources to upgrade and modernize facilities. Less than $27 \%$ of public institutions indicate too high costs of kitchen staff as the main reason for ordering function of feeding. Another reason is the need for financial savings ( $22 \%$ response rate). Some institutions indicate a desire to focus on key areas (20\% of responses) and lack of financial resources to upgrade and modernize the kitchen (20\% response rate). Public and private institutions exercise control over the quality and method performed by an external service (71\% of public institutions and $59 \%$ of private institutions). Private institutions often informally exercise external control (difference confirmed - Fisher's exact test). Less than $90 \%$ of public institutions indicated satisfaction with the services provided by external companies.

Conclusions: The adaptation of outsourcing in medical facilities leads to financial efficiency improvement. Through the separation of some medical functions and entrusting their realisation to external companies, medical institutions can focus on their basic activity that is the provision of health services.

Key words: outsourcing, medical entity, costs in health care.

\section{Introduction}

Modern health care management takes place in organizations and institutions that are becoming more and more complex [1]. The costs of health care in Poland are constantly rising. The main reasons for that increase are the low or even negative growth of the population and aging of the population [2]. Modern medicine has greatly succeeded in controlling, avoiding and even eliminating diseases [3]. Some ways to 
achieve that are prophylaxis and preventive examinations. Prevention programmes are the most comprehensive source of accurate information about the health of the population. Implementation of actions decreasing cardiovascular diseases is still one of the major public health challenges, due to the fact that these diseases are the first cause of death in Poland as well as in Europe and most developed countries. Prevention programmes contribute to the reduction of morbidity and mortality from cardiovascular disease and are a crucial element in tackling health inequalities in the world [4]. An older population requires much greater efforts to maintain proper health, defined not only as a lack of disease or disability, but also physical, mental and social well-being.

One of the cost rationalisation methods in the health care sector is outsourcing, namely a separation of certain activities from the medical institution and purchasing them from external entities [5].

Both medical and non-medical services can be contracted externally. Areas possible to separate in the field of providing health care services concern medical services, anaesthetic services, psychological services, medical gas, medicinal products and provision of medical devices.

The effects of outsourcing projects in health care can be divided into short-term and longterm effects. The first category includes cost reduction, changes in the organisational structure, improvement of its quality and access to new technologies and techniques of treatment. The quality measuring instruments are certificates and accreditation, but also such factors as services waiting time. The usage of equipment, and the value of specialised equipment purchase are technological measures.

A rise of medical care standards takes place through direct contact with the patient, conditions in which the patient stays in the ward, and introduction of new treatments. Quality of services has an influence not only on the image of a medical facility for patients, but also on the value of the contract received from the National Health Fund.

Quality improvement is also associated with the development of a therapeutic entity. Larger funds facilitate the assurance of better care standards, rapid access to specialists, purchase of more modern equipment or the introduction of modern treatment methods. Long-term effects relate to increase in economic efficiency - organisational development, improvement of quality of services and the medical entity's image.

The aim of the paper is to show that outsourcing is one of the methods aimed at cost reduction in medical entities and that there are differences between public and private institutions in the field of outsourcing usage.

\section{Material and methods}

The research was conducted in the years 2011 and 2012 in 153 institutions conducting medical activity randomly selected from the National Register of Medical Entities. The tool was an author's questionnaire. Questions in the questionnaire related to the experience of medical entities connected to outsourcing such services as cleaning, laundry, catering, waste disposal or property protection, as well as the reasons for commission of the above-mentioned services to external companies.

The research was conducted with the computer-assisted web interview (CAWI) technique. The questionnaire was available via a web browser. The respondents received a specially prepared message into their e-mail account, which directed them to a questionnaire generated separately for each respondent. The survey directed the respondents through each subsequent question, which was displayed in accordance with the logic of the answers provided. The respondents had a possibility to stop the survey at any moment and finish it at a different time. The survey was compatible with all popular web browsers. The architecture of the form allowed for its easy use on older computers, guaranteed safety of data storage and anonymity of the respondents.

\section{Results}

Over $30 \%$ of the public institutions indicated the necessity of introducing financial savings as the main reason for contracting the cleaning function to an external company (Figure 1). As a result of unlimited public demand and too low expenditure on health care, public institutions very frequently suffer from serious financial problems. In such a situation, most activities of the institution have to be subject to cost reduction. On the other hand, among the private institutions, the dominant reason is too high maintenance cost of the employees responsible for cleaning (almost $40 \%$ of the answers). Such institutions are profit-oriented and, thus, may not allow for any service generating costs. Both public $(20 \%$ of the answers) and private institutions (21\% of the answers) expressed their willingness to concentrate on the key areas, that is on the provision of health care services.

Among both the public and private institutions, the main benefits are financial savings (respectively $51 \%$ and 52\%) (Figure 2). Another advantage indicated by public and private institutions is an improvement in the quality of services provided (respectively $31 \%$ and $21 \%$ ). Although low quality of the service provided by the institutions' own employees was one of the rarest reasons for contracting the function of cleaning, the institu- 


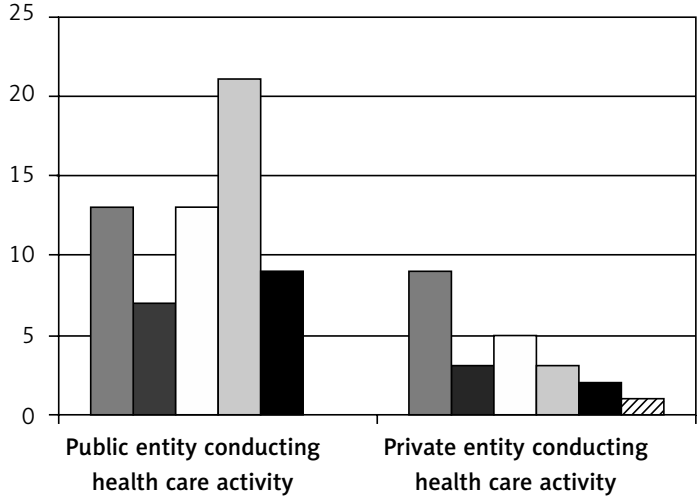

$\square$ Too high maintenance cost of employees responsible for cleaning

$\square$ Low quality of services provided by employees responsible for cleaning

$\square$ Willingness to concentrate the institution on its key areas

$\square$ Necessity to introduce financial savings

No funds for new machines used for cleaning

$\square$ Other, which?

Figure 1 . The cleaning function with regard to the type of medical entity - reasons for separating the function from the structure of the institution

tions noticed an increase in this quality. The least frequently appearing answer was a declaration of no noticeable benefits (about $5 \%$ of the answers).

Among both the public and private institutions, the most frequent answer is an opinion that such a solution does not have any disadvantages (respectively $48 \%$ and $57 \%$ of the answers). The most frequently noticed disadvantage is a decrease in service quality observed by almost $26 \%$ of the public institutions and $28 \%$ of the private

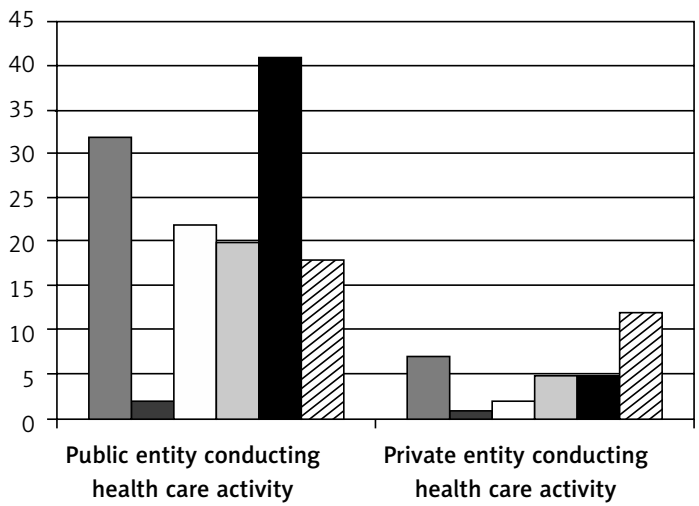

$\square$ Too high maintenance cost of employees responsible for washing

$\square$ Too low quality of services provided by employees responsible for washing

$\square$ Willingness to concentrate the institution on its key areas

$\square$ Necessity to introduce financial savings

No funds for modernisation of laundry

D Other

Figure 3. The washing function with regard to the type of medical entity - reasons for separating the function from the structure of the institution

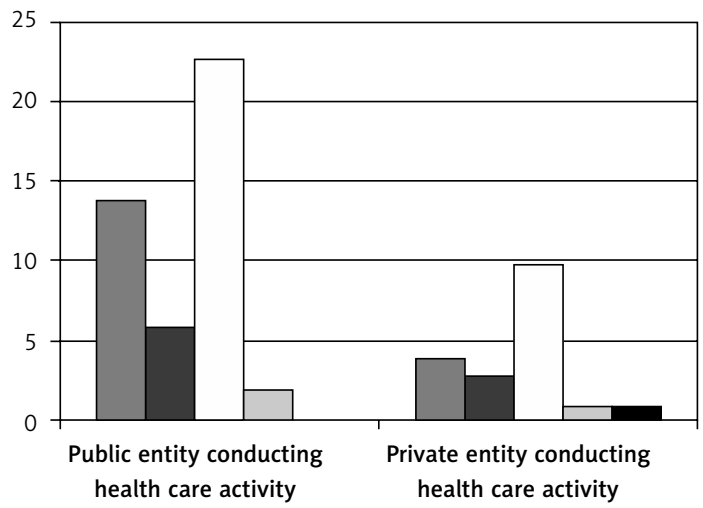

$\square$ Improvement in quality of services provided

$\square$ Improvement in sanitary conditions, influencing the work of other employees

$\square$ Financial savings

$\square$ I cannot see any benefits

- Other

Figure 2. The cleaning function with regard to the type of medical entity - benefits obtained by the institution in connection with the separation

ones. The respondents observed worse quality of the services provided by an external company compared to the quality of services provided by their own employees. Moreover, the public institutions noticed delays in provision of the service (almost $4 \%$ of the answers), which did not occur among the private institutions.

Over $30 \%$ of the public institutions indicated the lack of financial resources for modernisation of the laundry as the most frequent reason for separating the washing function (Figure 3). The reason for such a state may be the above-mentioned financial problems as well as the fact that, in a situation of the lack of financial resources, there are no possibilities for allocating funds to modernisation of the conditions of an activity not included in the key areas of the institution's activity. The second most frequently mentioned reason given by the public institutions for contracting the washing function to an external company is too high maintenance costs of the employees responsible for washing ( $24 \%$ of the answers). On the other hand, among the private institutions, the dominant reason is lack of their own laundry $37 \%$ of the answers). In such a situation, the institution does not have any other choice but outsourcing of the washing services. Both public and private institutions indicated the least frequently the low quality of services provided by their own employees responsible for washing as the reason for separating the function from the structure of the institution (respectively $1.5 \%$ and $3 \%$ of the answers).

Among both the public and private institutions, the main benefits are financial savings (respec- 
tively $53 \%$ and $44 \%$ of the answers). Another advantage of such a solution is an improvement in the quality of the services provided. It must also be emphasised that, among the public institutions, $15 \%$ cannot see any benefits related to separation of the washing function from the structure of the institution. Seven percent of the institutions availed themselves of the possibility to mention their own benefits, indicating saving of the working time and possibility to focus on the key tasks of the institution.

Among both the public and private institutions, the most frequent answer is an opinion that such a solution does not have any disadvantages (respectively $42 \%$ and $56 \%$ of the answers). The most frequently noticed disadvantage among the public institutions is delay in performance of the services, indicated by almost $22 \%$ of the respondents. Such reservations were most frequently reported by the institutions where the number of medical employees was about 100-200 people. Thirteen percent of the institutions availed themselves of the possibility to mention their own disadvantages, indicating missing or damaged bed linen as well as irregularity of the activity. On the other hand, the private institutions indicated not only the delays in the performance of the service, but also higher costs of the service. In this case, deterioration of the quality of the service performed, in contrast to the public institutions, is indicated by only $4 \%$ of the respondents.

Almost $27 \%$ of the public institutions mention too high cost of maintenance of the kitchen employees as the main reason for contracting the nu-

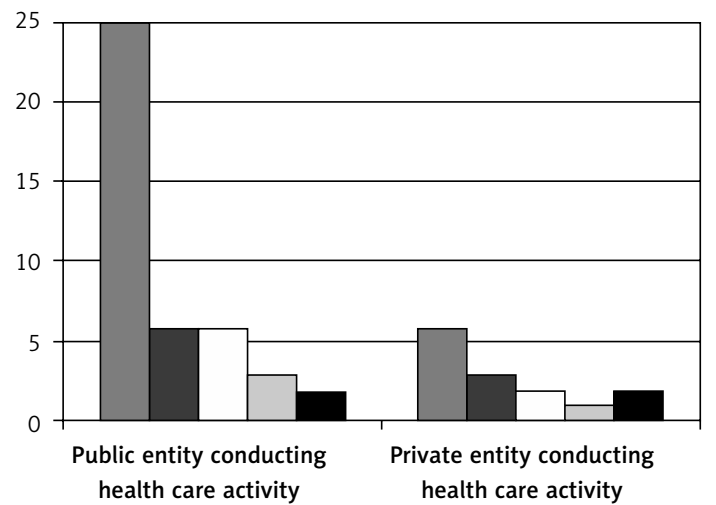

$\square$ Financial savings

$\square$ Higher level of employees' and patients' satisfaction with regard to meals eaten

$\square$ Improvement in quality of services provided

$\square$ Other

Don't see benefits

Figure 4. The nutrition function with regard to the type of medical entity - benefits obtained by the institution in connection with the separation trition function to an external company. Another reason is the necessity to introduce financial savings ( $22 \%$ of the answers). Both the first and the second reason are most frequently mentioned by the institutions with a maximum of 300 medical employees. The other institutions more frequently indicate the willingness to concentrate on the key areas ( $20 \%$ of the answers) as well as the lack of financial resources for modernisation of the kitchen ( $20 \%$ of the answers). Both the public and the private institutions mention too low quality of nutrition services as the least important reason. In this case quality is the least important issue, as in the face of a necessity to introduce financial savings, the priority is the cost of the service rather than its quality. On the other hand, the private institutions mentioned the necessity to introduce financial savings and the lack of financial resources for modernisation of the kitchen $(31 \%$ of the answers each) as the most frequent reasons for separating the nutrition function.

Among both the public and private institutions, the main benefits are financial savings, indicated respectively by $60 \%$ of the public institutions and $43 \%$ of the private ones (Figure 4 ). Among the public institutions, important benefits involve improvement in the quality of services performed and, thus, a higher level of employees' and patients' satisfaction with regard to the meals they eat (respectively $14 \%$ of the answers each). On the other hand, almost $22 \%$ of the private institutions indicated a higher level of employees' and patients' satisfaction with regard to the meals they eat. A similar percentage of the public and private institutions cannot see any benefits relat-

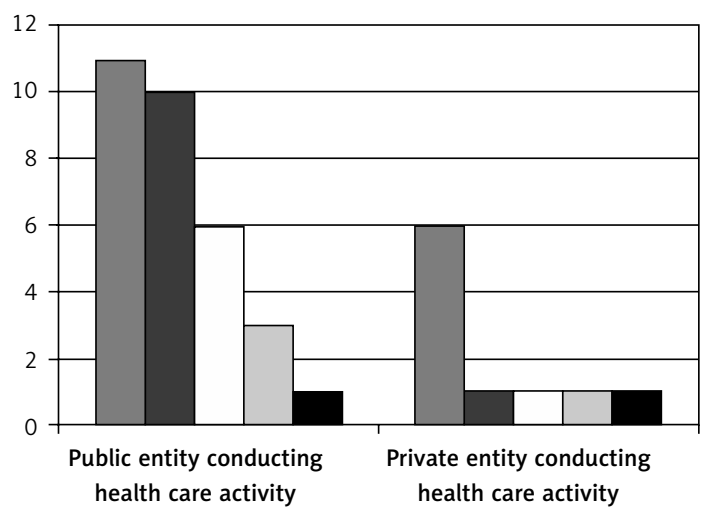

$\square$ Such a solution has no disadvantages

Decrease in the level of employees' and patients' satisfaction with meals eaten

$\square$ Deterioration in quality of services provided

$\square$ Other

- Higher cost of service

Figure 5. The nutrition function with regard to the type of medical entity - disadvantages of the separation 


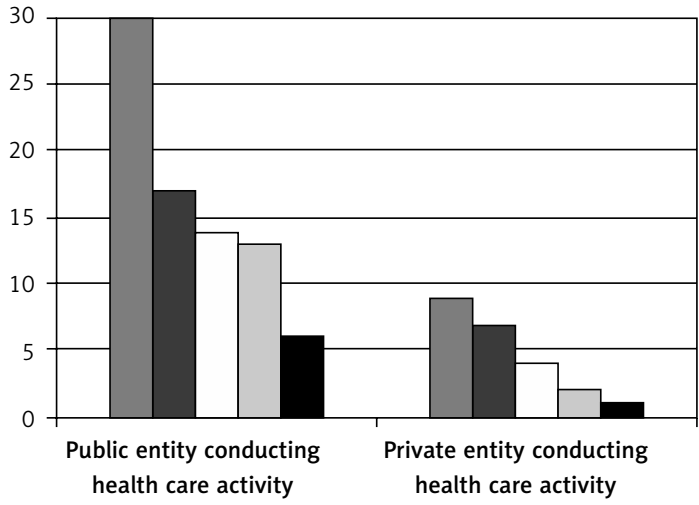

$\square$ We did not have our own property security employees

$\square$ Too high maintenance cost of employees involved in property security

$\square$ Willingness to concentrate the institution on its key areas

$\square$ Necessity to introduce financial savings

- Too low quality of services provided by institutions' own security employees

D Other

Figure 6 . The property security function with regard to the type of medical entity - reasons for separating the function from the structure of the institution

ed to separation of the nutrition function from the structure of the entity.

Among both the public and private institutions, the most frequent answer is an opinion that such a solution does not have any disadvantages (respectively $35 \%$ and $60 \%$ of the answers) (Figure 5 ). On the other hand, almost $32 \%$ of the public institutions indicated a decrease in employees' and patients' satisfaction with regard to the meals they eat, whereas among the private institutions, the percentage of each of the answers is $10 \%$. The pri-

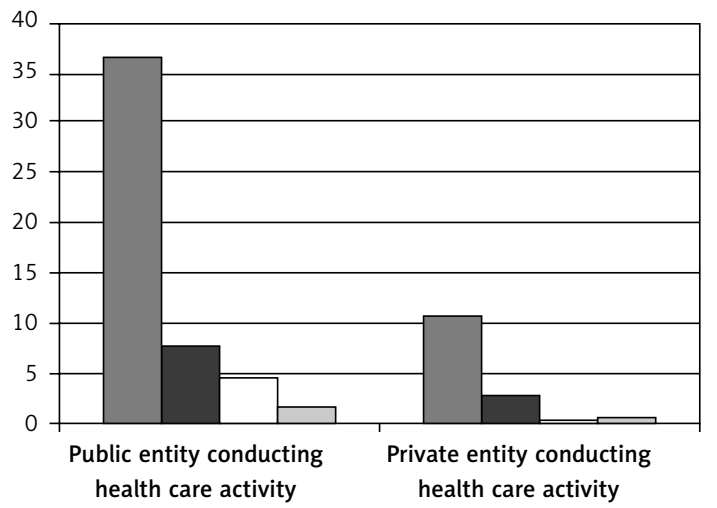

$\square$ Such a solution has no disadvantages

$\square$ Higher costs of service

$\square$ Deterioration in quality of services provided $\square$ Other

Figure 7 . The property security function with regard to the type of medical entity - disadvantages of the separation vate institutions equally often declare a decrease in the level of employees' and patients' satisfaction with regard to the meals they eat, deterioration of the quality of the services provided and higher costs of the service. In this situation, it is not possible to determine explicitly which of the above-mentioned disadvantages is the most important one. Nevertheless, taking into consideration the fact that the main reason indicated by the private institutions is the necessity to introduce financial savings, higher costs of the service may be considered as the main disadvantage.

Both the public and private institutions indicated the lack of their own security employees as the main reason (respectively $37 \%$ and $39 \%$ of the answers) (Figure 6). Such an answer was most frequently declared by the institutions where the number of medical employees was about 10-50 people. On the other hand, the institutions which had their own employees declared that too high cost of employee maintenance was the reason for contracting the property security function to an external company. Almost $18 \%$ of the respondents also indicate the willingness to concentrate the activity of the institution on the key areas. The least frequently given answer is too low quality of the services provided by their own property security employees, which was indicated by only $7.5 \%$ of the institutions. On the other hand, 30\% of the private institutions declared that too high cost of employee maintenance was the reason for contracting the property security function to an external company. Too low quality of the service is indicated by almost $5 \%$ of the respondents.

Among both the public and private institutions, the main benefit is improvement in the safety conditions (respectively $44 \%$ and $40 \%$ of the answers). Such an answer was most frequently declared by the institutions where the number of medical employees was about $10-50$ people. Almost $34 \%$ of the public institutions also indicate financial savings, whereas among the private institutions, the same percentage indicated financial savings as well as improvement in the quality of the services provided (respectively $22 \%$ of the answers each). Almost $14 \%$ also declare the lack of any benefits from outsourcing of the property security function.

Among both the public and private institutions, the most frequent answer is an opinion that such a solution does not have any disadvantages, indicated by $71 \%$ of the public institutions and $73 \%$ of the private ones (Figure 7). Fifteen percent of the institutions indicate higher costs of the service. Almost $10 \%$ of the public institutions declare deterioration in the quality of the services provided. Two respondents availed themselves of the possibility to mention their own disadvantages, 
declaring the low level of employees' involvement, the lack of identification with the facility as well as the fact that these employees cannot be entrusted with certain activities. On the other hand, the private institutions did not notice any deterioration in the quality of the services provided. $20 \%$ of the respondents indicated higher costs of the service.

Both the public and private institutions indicated the lack of their own activity related to waste disposal as the main reason (respectively $76 \%$ and $66 \%$ of the answers). Such an answer was most frequently declared by the institutions where the number of medical employees is within the range of 11-50 people. Among the private institutions, another reason is the lack of funds for modernisation of the material resources within the scope of waste disposal, which was indicated by almost $9 \%$ of the respondents. Such an answer was most frequently declared by larger institutions where the number of medical employees is within the range of 100-200 people. Among the private institutions, $10 \%$ of the respondents availed themselves of the possibility to indicate their own observations. The respondents declared the lack of formal and technical possibilities as well as the statutory requirements. The private institutions did not indicate too low quality of the services provided by their own employees within the scope of waste disposal as the reason for separation.

Among the public institutions, the main benefit is an improvement in the quality of the waste disposal services provided, indicated by almost 30\% of the respondents (Figure 8). Twenty-five percent of the public institutions also indicate financial savings. Over $20 \%$ of the institutions did not notice any benefits related to outsourcing of the waste disposal function. Nine respondents availed themselves of the possibility to mention their own observations, declaring protection from medical contamination and the possibility to focus on the basic activity. On the other hand, the highest percentage of the private institutions indicate improvement in the quality of the waste disposal services provided (30\%). The same percentage cannot see any benefits from such a solution. Four respondents availed themselves of the possibility to mention their own observations, indicating acting in accordance with the legal regulations as well as savings with regard to the construction of their own utilisation plant and price negotiations allowing for generation of significant benefits. The same percentage of the private institutions indicated financial savings as well as access to knowledge and technologies of the highest quality within the scope of waste disposal (16\% each).

Among both the public and private institutions, the most frequent answer is an opinion that such

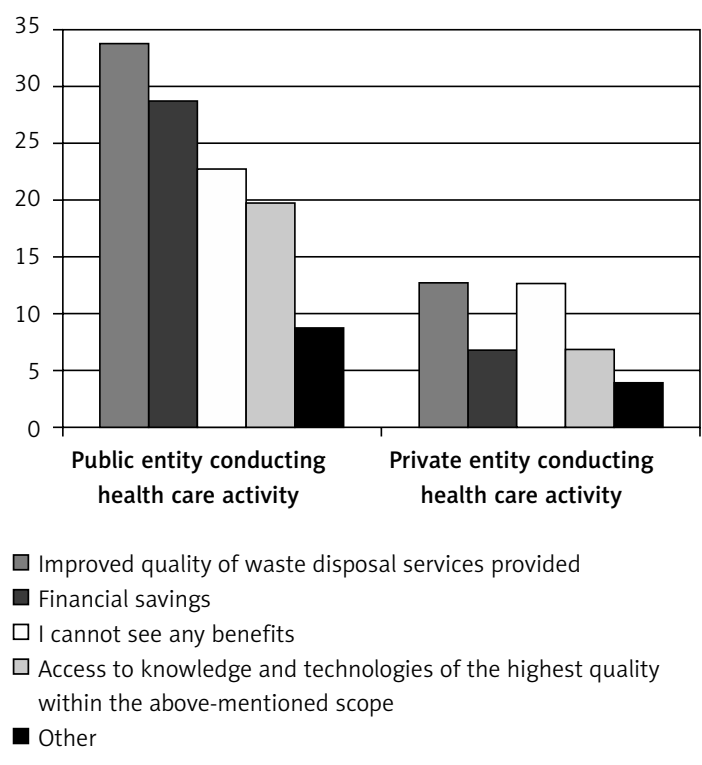

Figure 8. The waste disposal function with regard to the type of medical entity - benefits obtained by the institution in connection with the separation

a solution does not have any disadvantages, indicated by $81 \%$ of the public institutions and $80 \%$ of the private ones. Only $15 \%$ of the public institutions declare higher costs of the service. Four respondents availed themselves of the possibility to mention their own observations, indicating the lack of direct control with regard to waste handling and the statutory requirements. On the other hand, $25 \%$ of the private institutions indicate higher costs of the service.

Among the public institutions, 70\% exercise control over external companies (Figure 9). Almost $20 \%$ do not exercise such control. On the other hand, about $10 \%$ of the institutions do not have any information on whether control is exercised. As regards the private institutions, almost

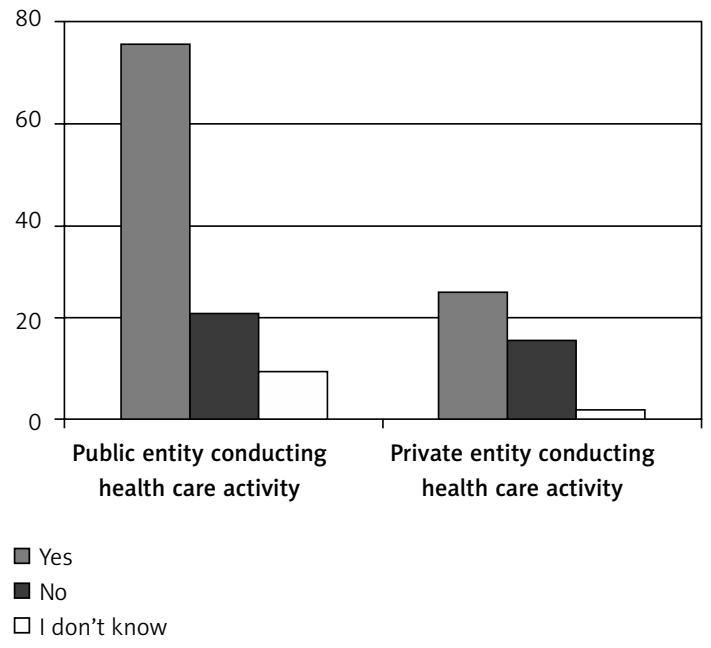

Figure 9. Monitoring of external companies and the type of medical entity 


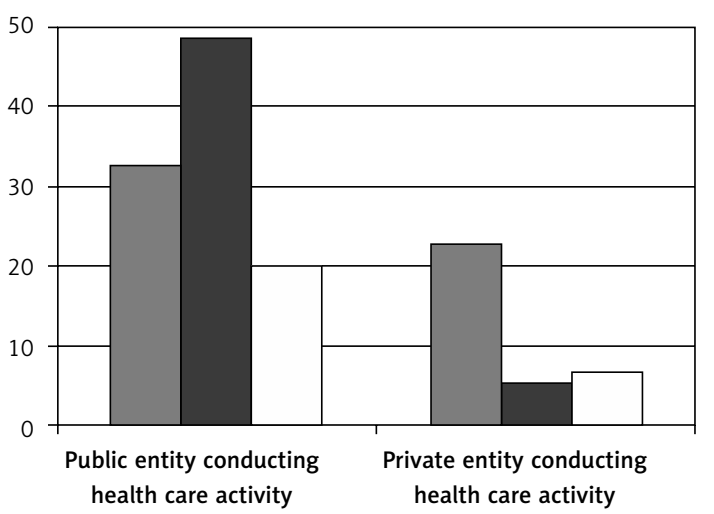

$\square$ Informal internal control

$\square$ Formalised evaluation based on service specificity $\square$ I don't know

Figure 10. Type of monitoring of external companies and the type of medical entity

$60 \%$ of them exercise control. Thirty-six percent of the institutions do not exercise any control of external companies, while almost 5\% do not have any information on whether control is exercised.

Almost $50 \%$ of the private institutions declare formalised evaluation based on the service specificity (Figure 10). Informal internal control is indicated by over $30 \%$ of the respondents, while almost $20 \%$ do not have any information on how control is exercised. On the other hand, the private institutions mostly (65\%) exercise informal internal control. Only $15 \%$ of the private institutions conduct formalised evaluation based on the service specificity. Twenty percent of the institutions do not have any information on how control is exercised.

\section{Discussion}

Both public and private institutions having experience with cleaning, washing, nutrition, waste disposal and security outsourcing indicate the financial aspects as the main reason for outsourcing. The necessity to introduce financial savings is one of the most frequently declared reasons for contracting the above-mentioned services to external companies.

A large majority of the public and private institutions have their own employees responsible for cleaning. Outsourcing of these services is still not very common. Nevertheless, the public entities which decided to contract the cleaning function to an external company had previously noticed too high maintenance costs of their own employees responsible for cleaning. In a situation of limited financial resources, the institutions are trying to look for savings within the scope of auxiliary functions. Although medical entities mostly express satisfaction with the quality of the services provid- ed by their own employees, they are forced to separate the auxiliary functions from their structure as they expect that outsourcing will allow them to make financial savings. The institutions under research very rarely indicate any disadvantages of separating the cleaning functions as a part of outsourcing and the main benefit gained by the public and private institutions is financial savings.

Another area subject to the analysis is the washing function. The vast majority of the medical institutions use the services of an external company within this scope. The public institutions very often do not have any financial resources to invest in modernisation of the laundry. On the other hand, the private institutions do not usually have any laundries. The private institutions are often small facilities, so ownership of a laundry is not profitable due to a small amount of washing. In such a situation, outsourcing of the washing service becomes a necessity. The private institutions notice many benefits within the analysed area, such as time saving and the above-mentioned financial savings. The institutions without their own laundries do not have any possibility to compare the services provided by an external company and those provided by their own employees. On the other hand, the public institutions usually have such a possibility. Making such a comparison, the public institutions indicate many disadvantages of outsourcing in the area of the washing function, such as missing bed linen, irregularity of services or delays in delivery of washing. Nevertheless, the benefits, which are mainly financial savings, exceed the indicated inconveniences.

Outsourcing of the nutrition function is still very rarely used among medical institutions. Health care entities usually have their own kitchen staff. Although the maintenance costs of their own employees is very high, the institutions are not willing to rent the kitchen to external companies. As regards outsourcing of the nutrition services, the institutions most frequently choose the purchase of ready-made meals provided by catering companies. In such a situation, the kitchen is excluded from use. The public institutions usually notice financial savings using this type of solution. Apart from the above-mentioned savings, many entities also gain improvement in the quality of the services provided and simultaneously higher level of patient and personnel satisfaction from the quality of meals. The benefit is of great significance as the level of medical personnel's satisfaction is reflected in the quality of their work. Also, for patients who often require a special diet, outsourcing of the nutrition function is an important benefit.

Another auxiliary function that was subject to analysis is property security. Most public insti- 
tutions contract the property security services to external companies. As regards the private institutions, the situation is the opposite. The main reason for separating the property security function is the lack of own employees. However, in the situation when the institutions have their own employees, they incur too high costs of their maintenance. In such an event, the institutions are forced again to look for an alternative solution which will reduce the cost of the service. Outsourcing of the property security function is the only one of the analysed services that does not bring financial savings as the main benefit. Nevertheless, this benefit is frequently noticed by the institutions. The most frequently obtained benefit is, in this case, an improvement in the safety conditions. A very small percentage of the health care entities notice disadvantages connected with this solution.

The research also involved the analysis of the waste disposal function. Very often, small institutions do not have their own activity connected with waste disposal. In such a situation, the only solution is outsourcing of these services. The private institutions also indicate the lack of technical possibilities as well as the statutory requirements. On the other hand, the public institutions do not have any funds for modernisation of the material resources within the scope of waste disposal. Outsourcing of the waste disposal function is connected not only with financial savings, but also with an improvement in the quality of the services provided. The institutions also notice positive aspects connected with protection from biological contamination. The only indicated disadvantage is the lack of direct control which the institutions could exercise having their own activity within this scope.

Over $70 \%$ of respondents are public entities, which represent the majority of Polish health care institutions. Taking them into account as a greater part of the research definitely gave a more objective view of outsourcing in institutions providing medical services. Public institutions control the quality and methods of services provided by external entities more often than the private ones. It is usually formalised evaluation based on the service specificity, whereas the private entities more often exercise informal internal control. Nearly $90 \%$ of public institutions declare satisfaction with the services provided by external companies. The other entities are partly satisfied or not satisfied at all. They only gained benefits with regard to some functions or did not gain any benefits at all. The situation may be connected with the choice of the outsourcing partner, the control of the service performance or too weak professional qualifications. As regards the private institutions, nearly $90 \%$ of them declare satisfaction with the services provided by external companies. None of the institutions indicated that it was dissatisfied with the manner or the quality of the services provided by the outsourcing partner.

World research corroborates these results. It shows that cost reductions are significant, at 10$15 \%$ in acquisition costs, and about $40 \%$ in transaction related costs [6]. Other research shows that outsourcing of some functions not directly connected with patient care can bring savings at the level of $20 \%$ or more. In general, it is estimated that health care organisations can save an average of about $23 \%$ on outsourcing contracts, but in some cases, it can reach even $45 \%$ [7].

In conclusion, the analysis indicates an improvement in the financial effectiveness due to outsourcing among the surveyed institutions. The most common functions separated by medical entities are washing, nutrition and waste disposal. However, outsourcing, like every method applied by medical entities, also has drawbacks. Therefore, before the introduction of outsourcing, detailed cost analysis of this activity should be carried out by hospital managers.

\section{References}

1. Schaller B. Scientific work and problem - solving in health care management: a way for the practitioner? Arch Med Sci 2012; 8: 817.

2. Lewandowska $\mathrm{H}$. Outsourcing model of management in entities of the hjealth care sector. Wydawnictwo Difin, Warsaw 2010; 200-9.

3. Schaller B, Sandu N. Clinical medicine, public health and ecological health: a new basis for education and prevention? Arch Med Sci 2011; 7: 541.

4. Bryła M, Maciak A, Marcinkowski JT, Maniecka-Bryła I. Prophylactic programmes in cardiovascular systems disorders as an example of levelling health status inequalities. Problemy Higieny i Epidemiologii 2009; 90: 6-17.

5. Kaustch M. Management in healh care. New challenges. Oficyna a Wolters Kluwer Business, Warsaw 2010; 299.

6. Guimarães CM, Carvalho JC. Outsourcing in health care sector - a state of the art review. The 8th International Conference on Logistics and SCM Research, Bordeaux, 29.09-1.10.2010; 6.

7. Gross G, Analyst: Outsourcing can save costs in health care. Available at: http://www.infoworld.com/t/business/ analyst-outsourcing-can-save-costs-in-health-care-886 (22.10.2012). 
Appendix 1.

\section{Questionnaire}

Department of Public Health of the Medical University of Warsaw is currently conducting a survey entitled Outsourcing as a method of cost rationalisation in public and non-public medical institutions as part of own research. For the needs of the survey, a questionnaire was prepared concerning the use of outsourcing by healthcare entities in Poland. It will only take you a few minutes to fill in the questionnaire. The questionnaire is anonymous, and the obtained information will only be used for scientific purposes. Thank you.

1. Are cleaning services in your institution provided by an external company?

$\square$ yes

$\square$ no (if no, please proceed to question number 2)

1.1. What was the reason for outsourcing the cleaning function to an external company? (you can select more than 1 answer)

$\square$ excessively high cost of maintaining employees responsible for cleaning

$\square$ low quality of services provided by the employees responsible for cleaning

$\square$ willingness to focus the institution's activities on core areas

$\square$ necessity to implement savings

$\square$ lack of funds needed to ensure modern methods and machines for cleaning

other, what?

1.2. How long has the cleaning function been performed by an external company?

$\square 0-12$ months

$1-2$ years

$2-5$ years

5 years and longer

1.3. What benefits has the institution achieved thanks to commissioning the cleaning function to an external company? (you can select more than 1 answer)

$\square$ improvement in quality of services

$\square$ improvement in sanitary conditions having impact on the work of other employees

$\square$ financial savings

$\square$ I don't see any benefits

other, what?.

1.4. What drawbacks have you noticed in connection with commissioning the cleaning function to an external company? (you can select more than 1 answer)

$\square$ decrease in quality of services

$\square$ delays in service performance

$\square$ higher costs of the service

$\square$ there are no disadvantages

$\square$ other, what?.

2. Are laundry services in your institution provided by an external company?

$\square$ yes

$\square$ no (if no, please proceed to question number 3)

2.1. What was the reason for outsourcing the laundry function to an external company? (you can select more than 1 answer)

$\square$ excessively high cost of maintaining employees responsible for laundry

$\square$ low quality of services provided by the employees responsible for laundry

$\square$ willingness to focus the institution's activities on core areas

$\square$ necessity to implement savings

$\square$ lack of funds for modernization of the laundry facilities

other, what?. 
2.2. How long have the laundry services been performed by an external company?

$\square 0-12$ months

$\square 1-2$ years

$2-5$ years

5 years and longer

2.3. What benefits has the institution achieved owing to commissioning the laundry function to an external company? (you can select more than 1 answer)

$\square$ improvement in quality of services

$\square$ financial savings

$\square$ I don't see any benefits

other, what?.

2.4. What drawbacks have you noticed in connection with commissioning the laundry function to an external company? (you can select more than 1 answer)

$\square$ decrease in quality of services

$\square$ delays in service performance

$\square$ higher costs of the service

$\square$ there are no disadvantages

other, what?.

3. Are catering services in you institution performed by an external company?

$\square$ yes

$\square$ no (if no, please proceed to question number 4)

3.1. What form do catering services take in your institution?

$\square$ renting out the kitchen to an external company and buying the meals prepared by that company

$\square$ buying meals delivered by a catering company (we do not have a kitchen or the kitchen is not used)

3.2. What was the reason for outsourcing the catering function to an external company? (you can select more than 1 answer)

$\square$ excessively high cost of maintaining kitchen employees

$\square$ low quality of catering services provided by the institution's employees

$\square$ willingness to focus the institution's activities on core areas

$\square$ necessity to implement savings

$\square$ lack of funds to modernize the kitchen

other, what?.

3.3. How long has the institution been using external catering services?

$\square 0-12$ months

$1-2$ years

$2-5$ years

$\square 5$ years and longer

3.4. What benefits has the institution achieved owing to commissioning the catering function to an external company? (you can select more than 1 answer)

$\square$ improvement in quality of services

$\square$ financial savings

$\square$ higher level of employee and patient satisfaction connected with the served meals

I don't see any benefits

other, what?.

3.5. What drawbacks have you noticed in connection with commissioning the catering function to an external company? (you can select more than 1 answer)

$\square$ decrease in quality of services

$\square$ lower level of employee and patient satisfaction connected with the served meals

$\square$ higher costs of the service

$\square$ there are no disadvantages

$\square$ other, what?. 
4. Are security services in you institution performed by and external company?

$\square$ yes

$\square$ no (if no, please proceed to question number 5)

4.1. What was the reason for outsourcing the security function to an external company? (you can select more than 1 answer)

$\square$ excessively high cost of maintain security employees

$\square$ low quality of security services performed by own security employees

willingness to focus the institution's activities on core areas

$\square$ necessity to implement savings

$\square$ we have never employed own security employees

other, what?.

4.2. How long has the security function been performed by an external company?

$\square$ 0-12 months

$\square 1-2$ years

$\square 2-5$ years

5 years and longer

4.3. What benefits has the institution achieved owing to commissioning the security function to an external company? (you can select more than 1 answer)

$\square$ improvement in safety conditions

$\square$ improvement in quality of services

$\square$ financial savings

$\square$ I don't see any benefits

other, what?

4.4. What drawbacks have you noticed in connection with commissioning the security function to an external company? (you can select more than 1 answer)

$\square$ decrease in quality of services

$\square$ higher costs of the service

$\square$ there are no disadvantages

other, what?

5. Are waste disposal functions in your institution performed by an external company?

$\square$ yes

$\square$ no (if no, please proceed to question number 6)

5.1. What was the reason for outsourcing the waste disposal function to an external company? (you can select more than 1 answer)

$\square$ lack of funds for modernization of waste disposal facilities and equipment

$\square$ obtaining access to the most advanced knowledge on modern methods of waste disposal

$\square$ low quality of waste disposal services performed by employees (failing to meet the requirements in the above area)

$\square$ necessity to implement savings

$\square$ we have never performed own waste disposal activities

$\square$ other, what?.

5.2. How long has the waste disposal function been performed by an external company?

$\square 0-12$ months

$\square 1-2$ years

$\square 2$ - 5 years

5 years and longer

5.3. What benefits has the institution achieved in connection with commissioning the waste disposal function to an external company? (you can select more than 1 answer)

$\square$ improvement in quality of waste disposal services

$\square$ financial savings 
access to best quality knowledge and technology in the above area

I don't see any benefits

other, what?.

5.4. What drawbacks have you noticed in connection with commissioning the waste disposal function to an external company? (you can select more than 1 answer)

$\square$ decrease in quality of services

$\square$ higher costs of the service

$\square$ there are no disadvantages

$\square$ other, what?.

6. Do you monitor the quality of services provided by external companies and the way they are provided? yes

no (if no, please proceed to question number 7)

$\square$ I don't know

6.1. How do you monitor the provision of services by external companies?

formalized assessment based on service-specific standards

$\square$ informal internal inspection

I don't know

7. Are you satisfied with the services provided by external companies?

$\square$ yes

$\square$ no

$\square$ partly, please list the services you are satisfied with:

\section{DEMOGRAPHICS:}

1. Institution :

public entity providing medical services

non-public entity providing medical services

2. Institution size (number of medical staff):

$\square 1-5$

$\square 6-10$

$\square 11-20$

$\square 21-50$

$\square 51-100$

$101-200$

$201-300$

$301-400$

$401-500$

$500-1000$

over one thousand

3. City (village) where the institution is located (population):

$\square$ village

$\square(0-20,000)$

$\square(20,000-100,000)$

$\square(100,0000-250,000)$

$\square(250,000-500,000)$

$\square(500,000-1,000,000)$

$\square$ Over $1 \mathrm{~m}$ 